\title{
Cosmetology Incision in Treatment of Benign Tumor of Breast: A Report of 1000 Cases
}

\author{
Mingqiang Han*, Lixian Yang, Shubo Chen \\ Department of Tumor Surgery, Xingtai People's Hospital of Hebei Province, Xingtai, China \\ Email: ${ }^{*}$ hanmingqiang@126.com
}

Received 26 May 2015; accepted 2 July 2015; published 6 July 2015

Copyright (C) 2015 by authors and Scientific Research Publishing Inc.

This work is licensed under the Creative Commons Attribution International License (CC BY).

http://creativecommons.org/licenses/by/4.0/

(c) (); Open Access

\begin{abstract}
Objective: To explore the selection of the best incision for operative treatment of benign breast tumor. Methods: The clinical data of 1000 cases of benign breast tumor operated by cosmetology incision were retrospectively analyzed. Results: All patients underwent tumor resection and were satisfied with the incision. Conclusions: Benign breast tumor can be excised through cosmetology incision, and no obvious scar leaves behind, so it can satisfy the cosmetic requirement of many patients.
\end{abstract}

\section{Keywords}

\section{Benign Breast Tumor, Cosmetology Incision, Cicatrix}

\section{Introduction}

Female breast benign tumor is a common clinical disease; it accounts for $80 \%$ of breast tumor [1]. The breast benign tumor is probably turned worse [2]. Operation is the main treatment method. Traditional surgical incision often chooses radial incision on the surface of the tumor, and can be arbitrary extension of the incision. It is very favorable for the exposure and resection of the tumor, and the treatment effect is also good, but the postoperative scar is obvious and affects the cosmetic effect. From Sep. 2006 to Sep. 2013, we had used cosmetology incision to treat 1000 patients of benign breast tumor, and obtained satisfactory therapeutic and cosmetic effects. Please refer to the following report.

\section{Materials and Methods}

\subsection{Patients}

All of 1000 patients are female; age: 14 - 63 years old, average 34 years old; the tumor located in the central

"Corresponding author.

How to cite this paper: Han, M.Q., Yang, L.X. and Chen, S.B. (2015) Cosmetology Incision in Treatment of Benign Tumor of Breast: A Report of 1000 Cases. International Journal of Clinical Medicine, 6, 465-468.

http://dx.doi.org/10.4236/ijcm.2015.67061 
area: 120 cases (12\%), located in the upper outer quadrant: 480 cases (48\%), located in the lower outer quadrant: 200 cases (20\%), located in the upper inner quadrant: 128 cases (12.8\%), located in the lower inner quadrant: 72 cases (7.2\%); The average tumor diameter is $1.6 \mathrm{~cm}(0.6-12 \mathrm{~cm})$, among that tumor diameter $<3 \mathrm{~cm} 550$ cases (55\%), $3.3-5 \mathrm{~cm} 374$ cases (37.4\%), $>5 \mathrm{~cm} 76$ cases (7.6\%); Pathologic diagnosis: fibroadenoma of breast 692 cases (69.2\%), cystic hyperplasia 125 cases (12.5\%), intraductal papilloma 114 cases (11.4\%), galactocele (part was combined chronic inflammation) 19 cases (1.9\%), fibroadenosis 34 cases (3.4\%), adiponecrosis 16 cases $(1.6 \%)$.

\subsection{Operation Methods}

Selection of incision operation: periareolar incision that from the areola $3 \mathrm{~cm}$ within the tumor, incision along the tumor underwent skin from a distance of more than $3 \mathrm{~cm}$ of the areola arc (Figure 1). If the tumor located in the glands deep, and the glands are thinner, no nursing requirements, it could space resection of the tumor trough the arc incision vertical incision.

\subsection{Operation Procedures}

Marking the location of the tumor and incision position and direction preoperative, the length of incision in general $2-3 \mathrm{~cm}$ (the large diameter of the tumor can be appropriately extended). Local infiltration anesthesia with $0.5 \%$ lidocaine by marking in turn cut the skin and subcutaneous tissue, Leave the fat layer, open radial gland, complete resection of the tumor and its coating, electro coagulation, without suture gland; 3 - 0 suture of subcutaneous tissue, 4 - 0 absorbable suture skin. No drainage, wound pressure dressing. Tumor located in the glands deep. If the glands are thinner, no nursing requirements, it could vertical incision to space resection of the tumor by the arc incision.

\section{Results}

Operation time 20 - 35 min, average 30 min. All the 1000 patients case can implementation of the curved surface or areola incision tumor successfully. All the 1000 patients' cases are well healed. Postoperative follow-up for 3 months to 3 years, underwent a B-ultrasonic examination, no obvious scar, symmetrical breasts, appearance and function had no effect when standing, the incision is not obvious, no residual tumor. Patients were satisfied for the clinical efficacy and breast appearance. Compared with the traditional incision in breast tumor resection compared, this operative method did not prolong the operation time, good cosmetic effect, and without increasing complications.

\section{Discussion}

For breast benign tumor located in the area around the areola, it should adopt the periareolar incision to remove

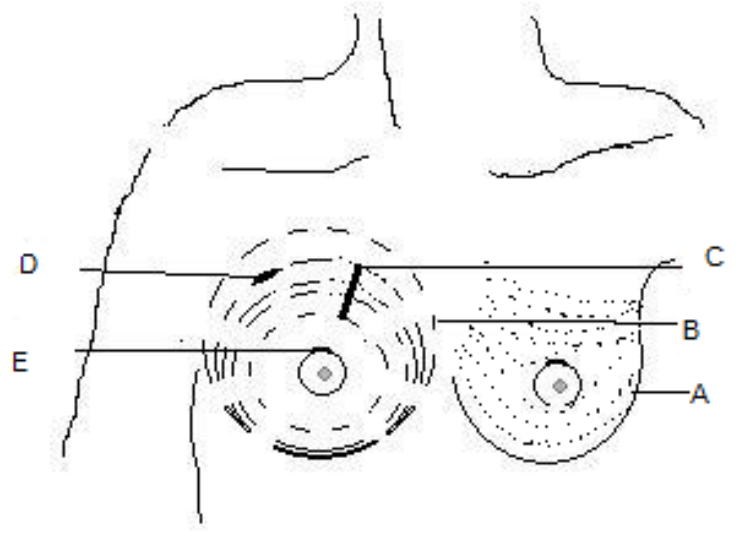

Figure 1. Breast Langer's line, the static tension line and incisions. A: Breast static tension line; B: Kerckring breast line; C: The traditional radial incision; D: The breast skin incision; E: Periareolar incision. 
the tumor. The method is no obvious controversy in line with the principle of cosmetcology and the cosmetic effect is also better than the traditional radial incision [3]-[5]. However for cutting the benign breast tumor far from bureau of areola, the traditional method of operative incision often is in the surface of the tumor and the areola is radial, the incision exposure well, easy operation, complete hemostasis, is not easy to stay dead space. But its drawback is leaving obvious scars on the breast skin after operation (Figure 2). It is affected women especially young women's breast appearance in a certain extent. Although the mammotome minimally invasive rotary cutting technology application is conformed to the requirements of the women of beauty, limit its widespread application in primary hospitals, because of the high cost, and it is only for less than $3 \mathrm{~cm}$ tumor.

For discussion of breast cosmetic surgery incision of benign tumor, FU Jianmin [6] adopts method of the breast fold incision and axillary incision to treat 275 cases, but it only used for the cases that the tumor located in breast lower quadrant and outer quadrant, and the surgical trauma is larger, more of the cases is needed drainage. ZHANG Yinghao [7] adopts method of manual tension cosmetic incision. It is that the assistant promotes the tumor to periareola, armpit or breast under the folds by tension during operation. It exists the defects including incomplete hemostasis, operation trauma, and easy to form subcutaneous hematoma. In addition, it cannot be resolved the tumor located in the upper quadrant, the author still suggests using traditional radial incision.

Surgical incision of breast benign tumor is divided into two parts of the skin incision and mammary gland incision. Ideal breast skin incision should be with the skin of static tension line parallel to or consistent [8]. According to the requirement of cosmeticology, incision of benign breast tumor was improved using periareolar incision or tumor surface along the striae of arc incision of skin incision (Figure 1). Because of the Langer' $s$ line and the breast with the static tension line is consistent, in accordance with the requirement for aesthetics, can be called to as cosmetic incision. And it also can be absorbed by intradermal suture line, it is small scar after operation (Figure 3). It is worth promotion in all size of hospitals because the incision in the surface of the

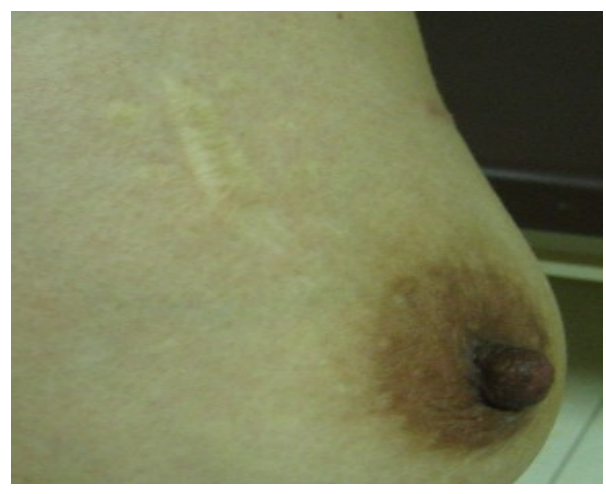

Figure 2. The traditional radial incision.

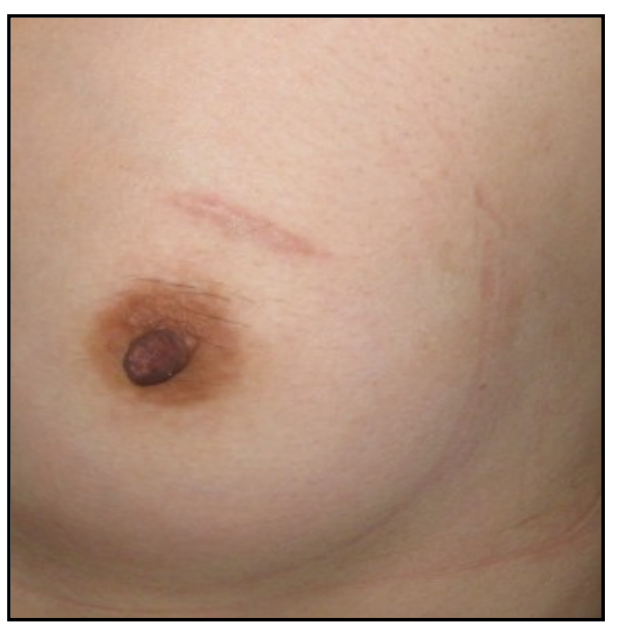

Figure 3. Cosmetology incision scar along the skin tension line. 
tumor exposed completely, convenient operation, thorough hemostasis, short operation time, less complications, low cost, and suitable for all the benign breast tumor.

\section{Conclusion}

All in all, benign breast tumor can be excised through cosmetology incision, and no obvious scar leaves behind, so it can satisfy the cosmetic requirement of many patients.

\section{References}

[1] Kopans, D.S. (1992) The Positive Value of Man Ography. American Journal of Roentgenology, 158, 521-526. http://dx.doi.org/10.2214/ajr.158.3.1310825

[2] Wu, J.P., Qiu, F.Z. and Huang, J.S. (2000) Surgery. 6th Edition, The People’s Health Press, Beijing, 830-831.

[3] Tao, X.F., Zhao, A.D. and Qin, J.Z. (2001) Areola Incision Breast Tumor Resection: Report of 858 Cases. Chinese Medical Cosmetology, 10, 319-320.

[4] Qi, F.Z. and Gu, J.Y. (2002) Aesthetic Choice of Breast Operation Incision. Chinese Journal of Medical Aesthetics and Cosmetology, 2, 35-36.

[5] Du, J.L. and Sun, H.Q. (2007) Periareolar Incision in the Treatment of Benign Breast Tumor: Attached 538 Cases Report. Chinese Journal of General Surgery, 16, 44-46.

[6] Fu, J.M., Zhang, W.X., Wang, E.L., et al. (2008) Occult Incision Resection of Benign Breast Tumor Surgery Technique. Guangdong Medical, 29, 842-843.

[7] Zhang, Y.H., Lin, L.C., Jiang, Z.G., et al. (2008) Experience in Manual Tension Cosmetic Incision in the Treatment of Mammary Gland Fibroma. Chinese Journal of General Surgery, 17, 513-524.

[8] Qi, F.Z. (2009) Breast Benign Tumor Operation Incision. Chinese Journal of Practical Surgery, 29, 278-279. 